\title{
Titanium Dioxide Nanoparticles for Enhanced Monocrystalline Solar Cell
}

\author{
Chiara Breda $^{a}$, Zahir Dehouche ${ }^{a}$, Abdulla Tahhan ${ }^{a}$, Tony Anson ${ }^{b}$, and George R. Fern ${ }^{c}$ \\ ${ }^{a}$ School of Engineering and Design, Brunel University, Uxbridge, UB8 3PH, UK \\ ${ }^{b}$ Experimental Techniques Centre, Brunel University, Uxbridge, UB8 3PH, UK \\ ${ }^{c}$ Wolfson Centre for Materials Processing, Brunel University, Uxbridge, UB8 3PH, UK
}

\begin{abstract}
Nanoparticles have recently been investigated as a possible way to improve absorption of light in solar cells. The strong interaction of nanoparticles with light allows control over the propagation of light at the nanoscale and thus, the design of solar cells, in which the light is trapped in an active layer and efficiently absorbed. This study investigates how a layer of $\mathrm{TiO}_{2}$ particles affect the performance of monocrystalline solar cells. A Titanium (Ti) layer was deposited on a monocrystalline solar cell and subsequently oxidised. Two different oxidation methods are used and compared: one sample of coated photovoltaic (PV) cell was heated in a furnace in contact with atmospheric air, the other by Plasma Enhanced Chemical Vapour Deposition (PECVD) using an oxygen rich compound, potassium permanganate. The results demonstrate that the oxidised layer influences electrical, morphological and antireflective properties of monocrystalline solar cells. The electrical characteristics of the solar cell improved with PECVD oxidising process as showed in the $J-V$ curves and the efficiency and the fill factor increased. Scanning Electron Microscope (SEM) analysis showed that the grain size changed using different sintering process and the solar reflectance of the monocrystalline solar cell was reduced after Titanium dioxide $\left(\mathrm{TiO}_{2}\right)$ deposition.
\end{abstract}

Index Terms-dielectric nanoparticles, monocrystalline silicon solar cell, nanocoating, PECVD, titanium dioxide.

\section{INTRODUCTION}

The continuing demand for energy has led many researchers to investigate alternative sources of clean energy [1]. Nanomaterials and nanostructures hold promise to enhance the performance of solar cells by improving both light-trapping and photo-carrier collection. Meanwhile, these new materials and structures can be fabricated using low cost techniques, to facilitate cost effective production of photovoltaics [2]. Recently, the use of dielectric nanoparticles has been theoretically demonstrated with the potential for further enhancement when compared to electrically conductive metallic nanoparticles [3].

Among the different loss mechanisms in a solar cell, heating of high energy photons $\left(\mathrm{E}_{\text {photon }}>\mathrm{E}_{g}\right.$ ) accounts for $47 \%$ loss [4]. This loss can be reduced to some extent using down conversion properties of nanostructures [5], [6]. With a down converting layer on the top of a monocrystalline solar cell, high energy photons will be absorbed to emit low energy photons. These photons are then absorbed efficiently by the solar cell below, resulting in increased conversion efficiency [7].

The ideal down-converting material for a silicon solar cell would absorb all photons greater than $2 \mathrm{Eg}$, and to re-emit these at an energy slightly greater than Eg, while remaining transparent to photons in the range Eg-2Eg. However, due to the low absorption coefficient of silicon ions, the most suitable host candidate would be a wide band gap semiconductor with a band gap of greater than $2.7 \mathrm{eV}$. This would ensure strong absorption of photons above the band gap and the carriers can relax from the conduction band down to the excited level of the silicon ion via energy transfer from the host [8].

A material that exhibits these characteristics is $\mathrm{TiO}_{2}$; it is a dielectric material with band gap in the range of 3.0-3.2 eV. It exists as three polymorphous structures, anatase, rutile and brookite, although for solar cell applications the greater band gap and high refractive index of anatase makes this structure most desirable, where the energy band gap is $\mathrm{Eg}=3.2 \mathrm{eV}$ and the refractive index is $n=2.5$. It has also been known that mesoporous anatase has an electron diffusion coefficient one order of magnitude higher than the rutile faction [9].

Other properties of $\mathrm{TiO}_{2}$ include its high refractive index, excellent transparency to visible, and near infrared light. Low maximum phonon energy $\left(\mathrm{h} v_{\max } \leq 650 \mathrm{~cm}^{-1}\right)$, should also exhibit minimal degradation from high energy photons due to its high chemical bond energy. The energy transfer from the $\mathrm{TiO}_{2}$ layer to silicon activators has been reported in the literature [10], [11]. The latter would allow photons with energy greater than the $\mathrm{TiO}_{2}$ band gap $(\mathrm{Eg}=3.05$ for the rutile phase) to be absorbed and their energy efficiently transferred to a silicon ion that has an excited state lying just below the $\mathrm{TiO}_{2}$ conductive band. It is clear that the properties of this absorbing layer strongly dependent on the porosity of the $\mathrm{TiO}_{2}$ [12].

A technique for preparing $\mathrm{TiO}_{2}$-film is to deposit a layer of titanium which is then oxidised by sintering at $400^{\circ} \mathrm{C}$ in air. This method has been used by Hammer [13] and was developed in Germany during the second world war for producing beam splitters which were known as "Steinheil 2" semi-transparent mirrors [13]. Another oxidising technique was investigated is using a strong oxidising agent, potassium permanganate $\left(\mathrm{KMnO}_{4}\right)$ placed in a low energy, diffuse plasma field: this PECVD based process, has the advantage of relatively low deposition temperature [14].

Certain properties of deposited oxide films have been investigated; when these oxide films are formed, their network structure is subject to considerable variations, which affect numerous properties of materials [13], including the optical ones. 
Titanium was deposited onto a monocrystalline solar cell by means of a thermal evaporator. After this, the deposited titanium was subjected to accelerated surface oxidation at elevated temperature, using a furnace, the other cell was oxidised by the thermal decomposition of potassium permanganate in the PECVD machine. This work describes the parameters that affect the electrical characteristics and optical properties of the oxidised films and how this influences the performance of silicon photovoltaic cells.

\section{EXPERIMENTAL PROCEDURE}

\section{A. Ti film preparation}

Monocrystalline solar cells XS156B3 from MOTECH were used. Before the coating, the cells were cleaned with isopropanol alcohol and tested to evaluate their base-line electrical properties. A thermal evaporator (Edwards E306A) was used to coat the cells with a thin $\mathrm{Ti} / \mathrm{TiO}_{2}$ nanolayer at a pressure of approximately $10^{-5}$ Bar. In the evaporation deposition, a titanium wire is heated to its melting point in a tungsten coil and subsequently evaporated by further heating. The evaporated titanium is then condensed on the substrate of the PV cell to a thickness of $7.9 \mathrm{~nm}$ was measured using a quartz crystal monitor.

\section{B. Oxidising by furnace}

A furnace (LINDBERG BLUE M, Thermo Scientific) was used to sinter the sample in air, at $400^{\circ} \mathrm{C}$ for 10 hour [13], this sample is termed sample (b) and (a) before the coating process. The furnace temperature was increased at a steady rate of $6^{\circ} \mathrm{C} / \mathrm{min}$, to avoid thermal shock and potential film fracture.

\section{Oxidising by PECVD}

The second sample was oxidised using a PECVD system and an oxidising compound, termed sample c). This low temperature process uses plasma in which the gases react in a glow discharge. This discharge ionizes the gases, creating active species that react at the sample surface. The discharge is generated between two separated pairs of electrodes in the shape of plates, at Radio Frequency (RF) of 13.56 megaHertz. Argon is used as plasma sources and $30 \mathrm{~g}$ Potassium Permanganate (by Fisher Scientific UK), shares the plasma environment; oxygen and other factions are then released from the compound and are co-deposited, with argon onto the sample. The oxidising agent $\mathrm{KMnO}_{4}$, is a purple crystalline solid that progressively decomposes with increasing temperatures forming a black powder consisting of a mixture of potassium and manganese dioxide, finally leading to the release of oxygen. The chemical reaction inside the chamber was:

$$
2 \mathrm{KMnO}_{4} \rightarrow \mathrm{K}_{2} \mathrm{MnO}_{4}+\mathrm{MnO}_{2}+\mathrm{O}_{2}
$$

First, the photovoltaic cell was placed on the cathode inside the vacuum chamber and positive ions of Argon gas energetically impinge on their surface. Total pressure and total gas flow rate are fixed at $3 \times 10^{-4}$ Torr and $25 \mathrm{sccm}$, respectively for a period of 60 minutes; the cathode voltage was set at $100 \mathrm{~V}$ and the power $15 \mathrm{~W}$.

\section{MEASUREMENTS}

\section{A. Electrical characteristic}

The electrical characteristics of the solar cells were tested at $25^{\circ} \mathrm{C}$ at different irradiances: $\mathrm{G}=404 \mathrm{~W} / \mathrm{m}^{2}, \mathrm{G}=572 \mathrm{~W} / \mathrm{m}^{2}$ with visible light and $\mathrm{G}=100 \mu \mathrm{W} / \mathrm{cm}^{2}$ with ultra-violet light. A Solar Power Meter (Di LOG-model: S102) instrument was used to check the visible irradiance and an UV light meter (LT Lutron-model: UV-340) instrument was used to check ultraviolet irradiance. All samples cells were tested using the same conditions.

The electrical characteristics of the photovoltaic solar cells were tested by connecting the cell with a resistive load (Array Electronic). The results are shown in the J-V and P-V curves diagrams. To calculate the J-V curves with UV light, cell area of $9 \mathrm{~cm}^{2}$ at $25^{\circ} \mathrm{C}$, while with the visible light cell area of 8.5 $\mathrm{cm}^{2}$ at $25^{\circ} \mathrm{C}$ was used. The efficiency $(\eta)$ and the Fill Factor (FF) were calculated.

\section{B. Reflectance}

Reflectance spectra were measured at room temperature using unpolarized light at normal incidence in a spectral range from 200 to $800 \mathrm{~nm}$. For this study, a Perkin-Elmer Lambda 650S UV-Vis spectrophotometer to measure total and diffuse reflectance was used.

\section{Optical Properties}

The crystalline phases of the products were determined by X-Ray Powder Diffraction (XRPD) using a Bruker D8 Advance X-ray powder diffractometer fitted with a nickelfiltered copper source and a LynxEye ${ }^{\mathrm{TM}}$ silicon strip detector. Data were recorded from 20 to $702 \theta$ degrees at $293 \mathrm{~K}$. The diffractometer was previously calibrated using an aluminium oxide line position standard from Bruker and LaB6 NIST SRM 660a line profile standard. The emission of the nickel filtered $\mathrm{Cu}$ source and hence the instrumental line broadening was determined by fitting the NIST standard using Bruker Topas version 3 software.

The film morphology is analysed using a ZEISS SUPRA 35VP field emission SEM. Energy dispersive X-ray analysis (EDX) was used to confirm the presence of the coating. The software used to analyse the surface is INCA.

\section{RESULT AND DISCUSSION}

The electrical performances of three samples were tested in the following order: a) uncoated, b) coated with $\mathrm{TiO}_{2}$ with increased oxygen content, using a sintering process in a furnace with atmospheric air and c) coated with $\mathrm{TiO}_{2}$ using a PECVD with an oxidising agent: these were tested under different irradiance and compared to each other.The three sample are named a) uncoated, b) $\mathrm{TiO}_{2}$ heated and c) PECVD oxidised.

The characteristic J-V and P-V curves of these monocrystalline solar cells are presented in Figs. 1 and 2, and the corresponding photovoltaic parameters are summarized in Table 1. 


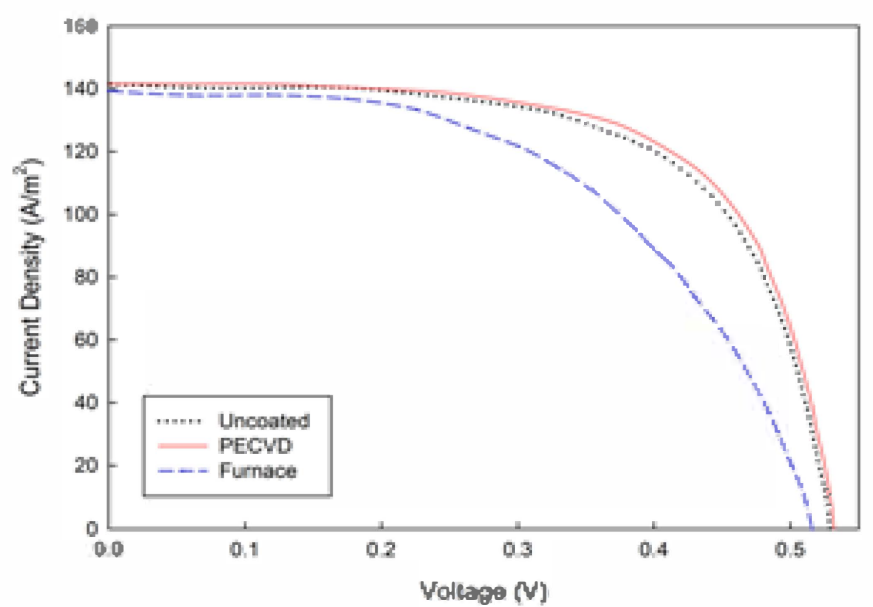

Fig. 1: J-V curves at $25^{\circ} \mathrm{C}$ and an Irradiance of $404 \mathrm{~W} / \mathrm{m}^{2}$.

At $404 \mathrm{~W} / \mathrm{m}^{2}$ the best electrical performance are shown in the sample c), it can be seen that the average open circuit voltage (Voc) and short circuit photocurrent density (Jsc) of the sample c) $\left(\mathrm{Voc}=0.532 \mathrm{~V}, \mathrm{Jsc}=141.54 \mathrm{~A} / \mathrm{m}^{2}\right)$ are higher than the sample b) $\left(\mathrm{Voc}=0.516 \mathrm{~V}, \mathrm{Jsc}=139.20 \mathrm{~A} / \mathrm{m}^{2}\right)$ and uncoated cell $\left(\mathrm{Voc}=0.529 \mathrm{~V}, \mathrm{Jsc}=141.54 \mathrm{~A} / \mathrm{m}^{2}\right)$. The fill factors reach identical values of about $65 \%$, except for the sample b), which is significantly reduced to $53 \%$. Concomitantly, the power conversion efficiencies increase from $11.9 \%$ to $12.23 \%$ for the sample c), on the other hand for the sample b) decrease to $9.46 \%$.

These results are expected because of the atmospheric heat treatment has a significant effect on the resultant oxide film in some systems [15]. The distinct photovoltaic behaviour of the sample b) shows a shading effect, the Voc and Jsc are lower than sample c) and uncoated cell.

The enhancement of electrical characteristics of the sample c) is due to the down conversion property of $\mathrm{TiO}_{2}$, which produces a photocurrent and a photovoltage under illumination. Another reason for the increase of Jsc is the enhanced absorption behaviour associated with the presence of aggregate, as seen in Fig. 9, resulting in higher photon absorption by way of light scattering. According to the scattering theory, effective Mie scattering happens to the particles with a size in the range of light wavelengths. Therefore, the enhanced absorption shown in the visible light is possibly due to light scattering of $\mathrm{TiO}_{2}$ aggregates.

At $570 \mathrm{~W} / \mathrm{m}^{2}$ the characteristic $\mathrm{J}-\mathrm{V}$ and P-V curves of these monocrystalline solar cells were measured and presented in Fig. 3 and 4. We decided to test the samples with different irradiances to see how the irradiance influences the electrical properties of the monocrystalline solar cell.

The best electrical performance, at $570 \mathrm{~W} / \mathrm{m}^{2}$ is shown in the uncoated sample. It can be seen that the short circuit photocurrent density (Jsc) of the uncoated cell a) $(\mathrm{Jsc}=273.72$ $\left.\mathrm{A} / \mathrm{m}^{2}\right)$ is higher than the sample $\left.\mathrm{b}\right)\left(\mathrm{Jsc}=257.35 \mathrm{~A} / \mathrm{m}^{2}\right)$ and the sample c) $\left(\mathrm{Jsc}=263.20 \mathrm{~A} / \mathrm{m}^{2}\right)$, while the average open circuit voltage $(\mathrm{Voc})$ of the uncoated cell a) $(\mathrm{Voc}=0.529 \mathrm{~V})$ is lower than the sample b) $(\mathrm{Voc}=0.547 \mathrm{~V})$ and the sample c) $(\mathrm{Voc}=0.552 \mathrm{~V})$. The fill factors reach identical values of about

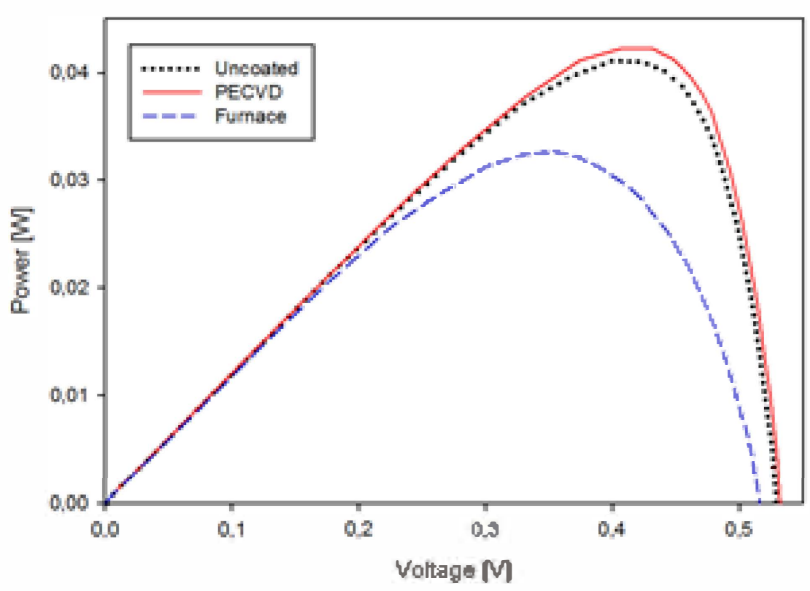

Fig. 2: $\mathrm{P}-\mathrm{V}$ curves at $25^{\circ} \mathrm{C}$ and an Irradiance of $404 \mathrm{~W} / \mathrm{m}^{2}$.

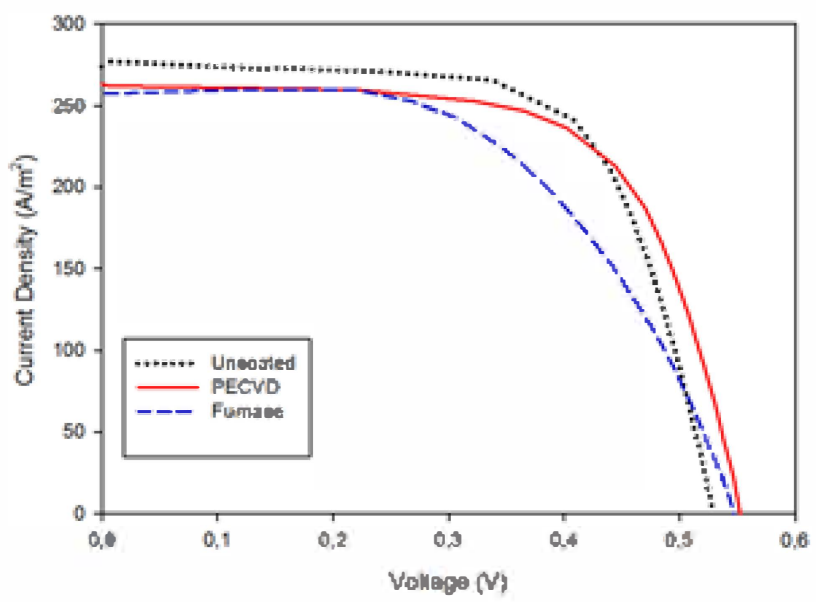

Fig. 3: J-V curves at $25^{\circ} \mathrm{C}$ and an Irradiance of $570 \mathrm{~W} / \mathrm{m}^{2}$.

$65 \%$, except for the sample b) which is significantly reduced to $56 \%$. Concomitantly, the power conversion efficiencies decrease from $17.41 \%$ to $16.61 \%$ for samples c) respectively. On the other hand, for sample b) a decrease to $13.84 \%$ was noted.

The Voc increase in the coated samples, which is due to the electron concentration gradient between the silicon wafer and $\mathrm{TiO}_{2}$ layer due to their size difference, which can confine the electrons in the silicon wafer, resulting in a suppressed recombination and a higher Voc [16].

The presence of $\mathrm{TiO}_{2}$ does not favour the electron transfer from $\mathrm{TiO}_{2}$ shell to silicon wafer due to the higher conduction band edge of $\mathrm{TiO}_{2}$, resulting in the Jsc decrease. However, the thickness of $\mathrm{TiO}_{2}$ is only $7.9 \mathrm{~nm}$ which facilitates tunnelling of the forward current while suppressing recombination.

At high irradiance, the heat treatment regime applied to sample b), has a significant effect on the resultant oxide film. The distinct photovoltaic behaviour of sample b) shows a shading effect, the Voc and Jsc are lower than sample c) and the uncoated cell. 


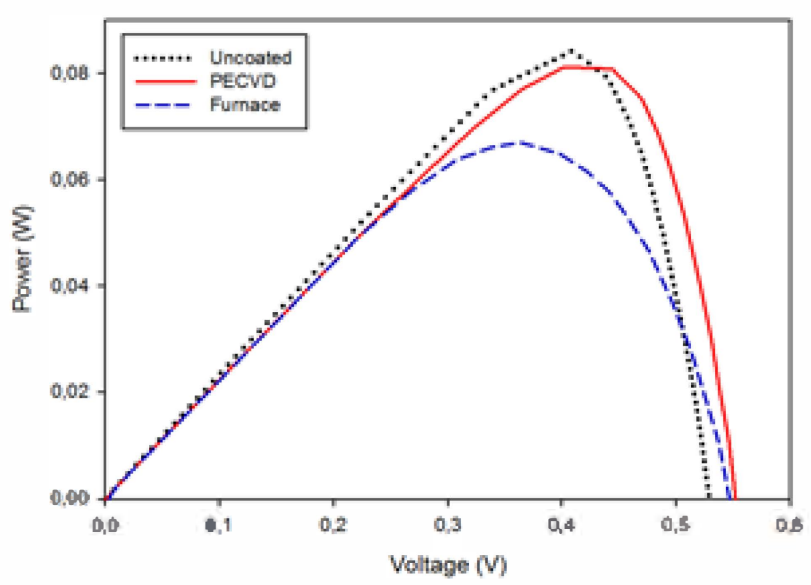

Fig. 4: $\mathrm{P}-\mathrm{V}$ curves at $25^{\circ} \mathrm{C}$ and an Irradiance of $570 \mathrm{~W} / \mathrm{m}^{2}$.

Table 1 Electrical charachteristics of the samples

\begin{tabular}{ccccccc}
\hline \hline Sample & $\begin{array}{c}\text { Jsc } \\
\mathrm{A} / \mathrm{m}^{2}\end{array}$ & $\begin{array}{c}\text { Voc } \\
\mathrm{V}\end{array}$ & $\begin{array}{c}\text { Pmax } \\
\mathrm{mW}\end{array}$ & $\begin{array}{c}\text { F.F. } \\
-\end{array}$ & $\begin{array}{c}\eta \\
\%\end{array}$ & $\begin{array}{c}\eta_{U V} \\
\%\end{array}$ \\
\hline \hline (a) & 141.54 & 0.529 & 41.1 & 0.64 & 11.90 & 14.63 \\
(b) & 139.20 & 0.516 & 32.6 & 0.53 & 9.46 & 13.89 \\
(c) & 141.54 & 0.532 & 42.2 & 0.65 & 12.23 & 11.08 \\
\hline \hline
\end{tabular}

The samples were tested with an UV light at of $100 \mu \mathrm{W} / \mathrm{cm}^{2}$ as shown in Figs. 5 and 6. The best electrical performance, at $100 \mu \mathrm{W} / \mathrm{cm}^{2}$, are observed with the uncoated sample a); we can see that the average open circuit voltage (Voc) and short circuit photocurrent density (Jsc) of sample a), uncoated $\left(\mathrm{Voc}=0.480 \mathrm{~V}, \mathrm{Jsc}=48.89 \mathrm{~A} / \mathrm{m}^{2}\right)$ are higher than sample b), $\left(\mathrm{Voc}=0.502 \mathrm{~V}, \mathrm{Jsc}=40 \mathrm{~A} / \mathrm{m}^{2}\right)$ and sample $\left.\mathrm{c}\right),(\mathrm{Voc}=0.477 \mathrm{~V}$, $\mathrm{Jsc}=40 \mathrm{~A} / \mathrm{m}^{2}$ ). The fill factors reach identical values of about $60 \%$, except for the sample b), which is slightly better (69\%). Concomitantly, the power conversion efficiencies decrease from $14.63 \%$ for uncoated sample to $13.89 \%$ for the sample b), on the other hand for the sample c) decrease to $11.08 \%$.

In this case the worst performances are shown by the sample c), this result was expected because it is a direct effect of down conversion of titanium dioxide, and thus the high energy photons were absorbed to emit low energy photons. The ultraviolet (UV) light spectrum range starts from the visible $(400 \mathrm{~nm}, 3.1 \mathrm{eV})$ and reaches the X-ray spectrum, low energy frontier $(10 \mathrm{~nm}, 124 \mathrm{eV}) . \mathrm{TiO}_{2}$ with band gap $3.2 \mathrm{eV}$ captures the ions with equivalent charge and emits visible light; this is evidenced in the worst performance of the sample c).

\section{A. Optical measurement}

The spectra range measured covers UV, visible and infrared wavelengths. A low reflectance percentage is desirable as it would result in higher absorption of light by the cells. Fig. 7 shows the reflectance spectra of three different simples: uncoated a), coated with $\mathrm{TiO}_{2}$ using a sintering process by furnace termed sample b) and additional oxygen coated $\mathrm{TiO}_{2}$ using PECVD derived oxygen deposition termed sample c).

The atmospheric heat treatment has a significant effect on the resultant oxide film in some systems. Yoldas [15] observed

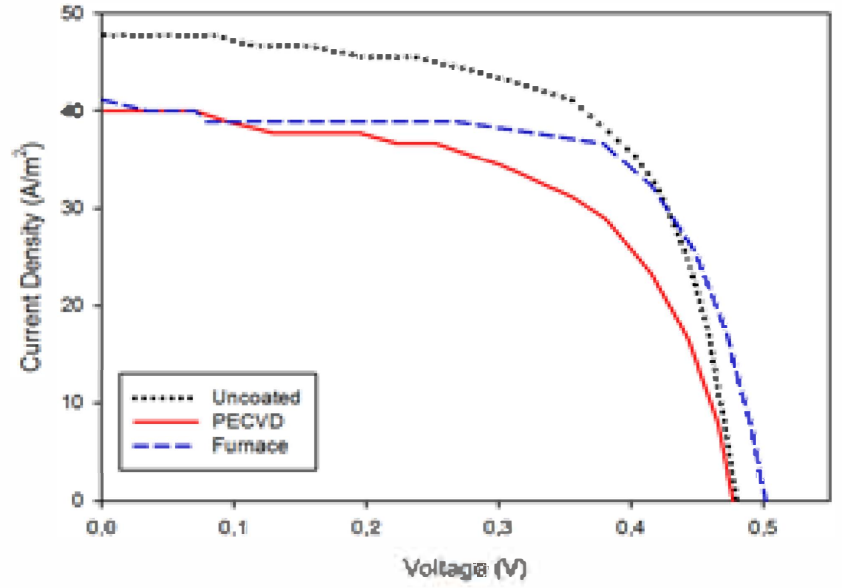

Fig. 5: $\mathrm{J}-\mathrm{V}$ curves at $25^{\circ} \mathrm{C}$ and an Irradiance of $100 \mu \mathrm{W} / \mathrm{cm}^{2}$.

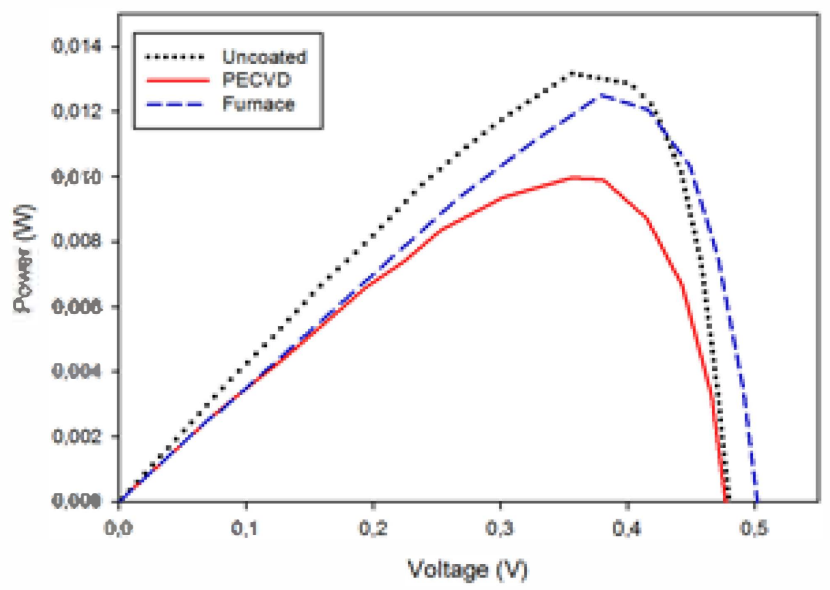

Fig. 6: $\mathrm{P}-\mathrm{V}$ curves at $25^{\circ} \mathrm{C}$ and an Irradiance of $100 \mu \mathrm{W} / \mathrm{cm}^{2}$.

that higher refractive index was obtained when $\mathrm{TiO}_{2}$ films were heated in a vacuum instead of in air. It can be clearly observed that the use of the PECVD machine during the oxygen deposition process improves the antireflective properties of the $\mathrm{TiO}_{2}$ film for silicon solar cells. This can be due to a better matching between the refractive index in both the film and the substrate. Another way to explain the significantly lower reflective index in the sample c) is apparently due to increased densification resulting from the thermochemical reaction in the absence of atomic oxygen: in fact in the presence of oxygen these bonds will not be forced to share oxygen and will, therefore, create a less dense oxide network [15].

The range of the visible light that responds to wavelengths from about 390 to $700 \mathrm{~nm}$ shows the same reflectance for both cells: coated and uncoated. It is observed that in the UV region the reflectance of the coated PV cells in PECVD is reduced compared to the uncoated one. This suggests that more light is absorbed and the treated cells can be considered to have an antireflective change [12].

If we compare only the coated cells, there is a different behaviour in the ultraviolet range that responds to wavelengths from about $200 \mathrm{~nm}$ to $390 \mathrm{~nm}$. There are three distinct 


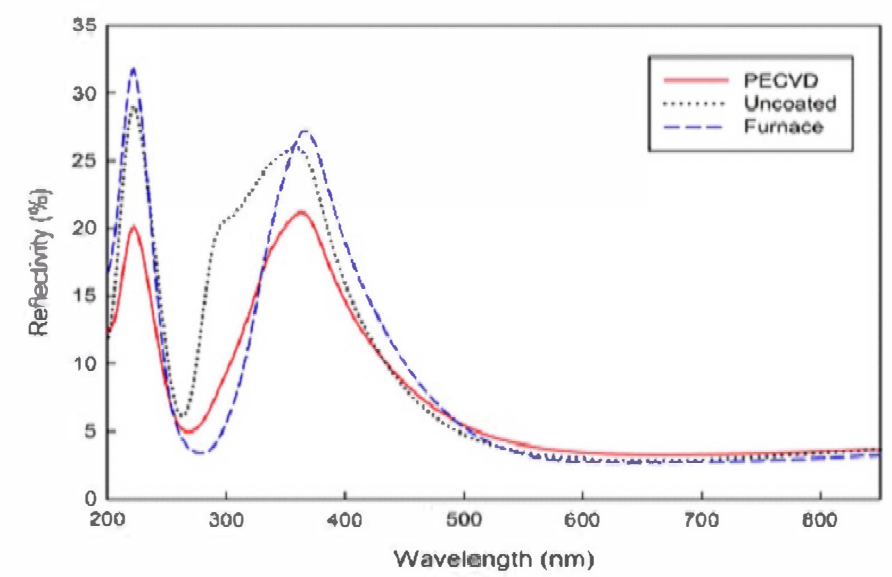

Fig. 7: Reflectance spectra for uncoated cell sample a), cell coated with $\mathrm{TiO}_{2}$ heated sample b) and PECVD oxidising sample c).

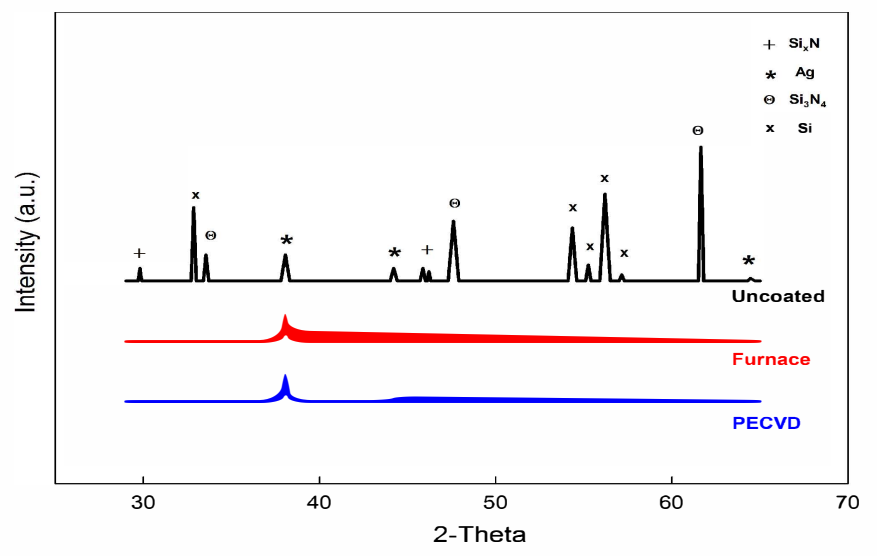

Fig. 8: XRD spectra for uncoated cell, coated cell with $\mathrm{TiO}_{2}$ in furnace and coated cell with $\mathrm{TiO}_{2}$ in PECVD.

regions. The first region between 200 to $254 \mathrm{~nm}$ wavelengths shows that the reflectance of sample c) is significant reduced compared to sample b) and uncoated cell. The second region between 254 to $330 \mathrm{~nm}$ wavelengths shows an opposite behaviour: the reflectance of the sample b) is reduced most; sample c) is not significantly reduced. The third region between 330 to $400 \mathrm{~nm}$ wavelengths shows that the reflectance of the sample c) is reduced than the sample b) slightly increased. At longer wavelengths measured the PV cells all had similar behaviour and relatively lower reflectance. The changes in the reflectivity of the PV cells occur only in the UV range.

\section{B. Structural and morphological properties}

Fig. 8 shows the X-ray crystal structure analysis carried out on the monocrystalline cell surface before and after coating. The patterns after coating reveal $\mathrm{Si}$ and Si-based peaks disappearance; this can be ascribed to $\mathrm{TiO}_{2}$ nano-films amorphization, and suggesting that the thin film of $\mathrm{TiO}_{2}$ have a low reflective index [15].

Finally, the influence of the different sample processing methods has been studied using SEM. Two different cells are

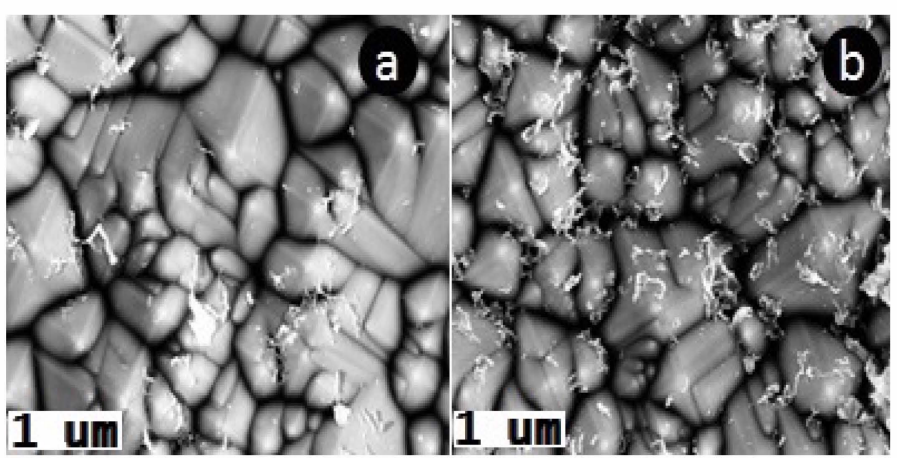

Fig. 9: SEM Micrograph of $\mathrm{TiO}_{2}$ Sintered in the Furnace b) SEM micrograph of $\mathrm{TiO}_{2}$ sintered in PECVD machine.

shown; in Fig. 9 (a) coated cell with $\mathrm{TiO}_{2}$ after furnace heat treatment and (c) coated cell with $\mathrm{TiO}_{2}$ with oxidising process in PECVD machine, where we can see the different sizes of amorphous $\mathrm{TiO}_{2}$.

The surface condition of substrates affects the orientation and packing of molecules; the diffusion of various species into the optical film from the substrate occurs during the bake. A smooth polished silicon surface promotes alignment and denser packing of molecules [15]. The cell oxidised using PECVD process, shows a more dense and homogeneously distributed coating (see Fig. 9). The elemental quantities are summarized in Table 2 (All results are in weight percentage).

Table 2 Elemental surface composition

\begin{tabular}{cccccc}
\hline \hline Sample & $\mathrm{N}$ & $\mathrm{O}$ & $\mathrm{Si}$ & $\mathrm{Ti}$ & Total \\
\hline (a) & 17.52 & 1.25 & 81.22 & - & 100 \\
(b) & 17.42 & 1.86 & 80.41 & 0.31 & 100 \\
(c) & 11.71 & 4.69 & 83.29 & 0.31 & 100 \\
\hline
\end{tabular}

\section{CONCLUSION}

In this paper we have demonstrated the effect of different processing conditions and methods for measuring the electrical, optical and morphological properties and performance of monocrystalline PV cells. Ti layers were deposited by thermal evaporation on commercial silicon PV cells and subsequently oxidised with two different processes.

A $7.9 \mathrm{~nm}$ Ti layer thickness was measured and amorphous $\mathrm{TiO}_{2}$ films were created. One sample was sintered in the furnace under atmospheric air and the other has additional oxygen applied by evolving the gas from a precursor compound, potassium permanganate; the processing parameters in the furnace or PECVD machine influence drastically the electrical characteristics and optical properties of the PV cells. Efficiency enhancements have been observed in monocrystalline silicon solar cells with deposition of $\mathrm{TiO}_{2}$ using PECVD. A relative increase in power conversion efficiency of $2.8 \%$ in visible light has been measured. This demonstrates that $\mathrm{TiO}_{2}$ coating created with PECVD oxidising process contribute to efficiency enhancement of solar cells at lower irradiance without adding much to the manufacturing cost. The electrical characteristics of the monocrystalline silicon solar cell were tested with different irradiances. 
The lower irradiances are particularly interesting because are the same that we can find in the Europe area; in this case an enhancement of efficiency is really relevant. It has been observed that the deposition of $\mathrm{TiO}_{2}$ film on monocrystalline silicon solar cell prepared with the PECVD process reduces the reflectance. This can be due to a better matching between the refractive index in both the film and the substrate. Furthermore, the use of PECVD during the oxidising process improves the antireflective properties. The layer of the cell oxidised in PECVD process which shows a different structure on a microscopic scale is more homogeneous than the others as shown in the SEM pictures.

\section{REFERENCES}

[1] K. D. Rogers, D. W. Lane, J. D. Painter, and A. Chapman, "Structural characterization of sprayed $\mathrm{TiO}_{2}$ film for extremely thin absorber layer solar cells," s.l. : Thin solid film 466 97-12, 2004.

[2] Z. Fann, R. Yu, Q. Lin, and S. Leung, "Nanomaterials and nanostructures for efficient light absorption and photovoltaics," 7 November 2011.

[3] Yu. A. Akimov, W. S. Koh, S. Y. Sian, and S. Ren, "Nanoparticleenhanced thin film solar cells: Metallic or Dielettric nanoparticles?," s.l. : Applied Physics letters 96,073111, 18 February 2010.

[4] M. C. Beard, K. P. Knutsen, P. Yu, J. M. Luther, Q. Song, and W. K. Metzger, "Multiple Exciton Generation in Colloidal Silicon," s.l. : NanoLetters7, 2506-2512, 2007.

[5] T. Trupke, M. A. Green, P. Wurfel, "Improving solar cells efficiencies by down," s.l. : Journal of Applied Physics 92 1668-1674, 2002.

[6] M. A. Green, Third Generation Photovoltaics : Advanced Solar Energy Conversion. s.l. : Springer p.107, 2006.

[7] W. R. Taube, A. Kumar, R. Saravanan, P. B. Agarwal , P. Kothari, B. C. Joshi, and D. Kumar, "Efficiency enhancement of silicon solar cells with silicon nanocrystals embedded in PECVD silicon nitride matrix," s.l. : Solar Energy Materials \& Solar Cells, 9 March 2012.

[8] B. S. Richards, Luminescent layers for enhanced silicon solar cell performance: Down-conversion. s.l. : Solar Energy Materials \& Solar Cells 90 (2006) 1189-1207, 29 August 2005.

[9] S. Kambe, S. Nakade, Y. Wada, T. Kitamura, and S.Yanagida. s.l. : Mat. Chem. $12-723,2002$

[10] K. L. Frindell, M. H. Bartl, A. Popitsch, and G. D. Stucky. "Sensitized luminescence of trivalent europium by three-dimensionally arranged anatase nanocrystals in mesostructured titania thin films,". s.l. : Angew.Chem. Int. Ed. 41 959-962., Jun 2002.

[11] K. L. Frindell, M. H. Bartl, M. R. Robinson, G. C. Bazan, A. Popitsch, and G. D. Stucky. "Visible and near-IR luminescence via energy transfer in rare earth doped mesoporous titania thin with nanocrystalline walls," s.l. : J. Solid State Chem. 172 81-88.

[12] G. San Vicente, A. Morales, and M. T. Gutiérrez, "Sol-gel TiO2 antireflective films for textured monocrystalline silicon solar cells," s.l. : Thin solid film 403-404 335-338, 2002.

[13] L. Holland, Vacuum Deposition of Thin Films. s.l. : Chapman \& Hall Ltd., 1956.

[14] P. H. Wu, I. K. Lin, H. Y. Yan, K. S. Ou, K. S. Chen, and X. Zhang, "Mechanical property characterization of sputtered and plasma enhanced chemical deposition (PECVD) silicon nitride films after rapid thermal annealing," s.l. : Sensors and Actuators A: Physical, 2011.

[15] B. E. Yoldas, "Deposition and properties of optical oxide coatings from polymerized solutions," s.l. : Appl. Opt. 21. Vol. 16, 1982. 2960.

[16] K. Park, Q. Zhang, B. B. Garcia, X. Zhou, Y. H. jeong, and G. Cao, Adv. Mater. 2010. Vol. 2329-2332, 22. 